\title{
Estereotipias motoras e linguagem: aspectos multimodais da negação no autismo
}

\section{Motor Stereotypies and language: multimodal aspects of negation in autism}

Isabela Barbosa do Rêgo Barros*

Universidade Católica de Pernambuco

Recife, Pernambuco, Brasil.

Renata Fonseca Lima da Fonte

Universidade Católica de Pernambuco

Recife, Pernambuco, Brasil.

RESUMO: Estereotipias motoras podem representar índices de constituição da linguagem do sujeito diagnosticado com Transtorno do Espectro Autista. Entendemos o autista como sujeito constituído na/pela linguagem, e esta enquanto funcionamento multimodal. Partimos do estudo de caso de uma criança autista participante do Grupo de Estudos e Atendimento ao Espectro Autista - GEAUT/UNICAP para discutir o lugar do autista na linguagem considerando os movimentos de negação que apresentam diferentes configurações multimodais do 'não' no autismo. Nos dados encontrados constatamos que as estereotipias motoras e vocalizações com sentido de negação representam recursos multimodais enunciativos de sujeitos autistas na linguagem.

PALAVRAS-CHAVE: autismo; estereotipias motoras; multimodalidade.

ABSTRACT: Motor stereotypies may represent an indication of the constitution of language by a subject diagnosed with Autism Spectrum Disorder. We understand the autist as a subject constructed in / through language, and this as a multimodal operation. We begin with the case study of an autistic child participant in a Study Group and Autistic Spectrum Care - GEAUT/UNICAP to discuss the place of an autist within language, considering the negation movements that present different multimodal settings of 'not' in autism. In the collected data, we found that motor stereotypies and vocalizations with a sense of negation represent multimodal enunciative resources of autistic subjects within language.

KEYWORDS: autism; motor stereotypies; multimodality.

\footnotetext{
*ibelabarros@gmail.com

** renataflfonte@gmail.com
} 


\section{Introdução}

Após quatorze anos de revisão, o DSM V, compêndio médico publicado em sua quinta edição no ano 2013 pela Associação Americana de Psiquiatria, define o autismo como uma das categorias de transtorno inserida no grupo dos Transtornos do Espectro Autista (TEA). Apresenta-o como um distúrbio de socialização com início precoce, que afeta simultaneamente o estabelecimento da subjetividade, da linguagem e das capacidades adaptativas.

O período dos primeiros registros sobre o autismo compreende do final da década de 1930 ao início da década de 1940, a partir das observações do pesquisador e psiquiatra infantil Leo Kanner, que analisou um grupo de onze crianças com idades entre dois e onze anos, assistidas por ele no Johns Hopinks Hospital, Estados Unidos. Em comum, as crianças apresentavam alterações na linguagem e dificuldade na interação social, caracterizadas por tendência ao isolamento e indiferença a pessoas, objetos e situações cotidianas, uso inadequado da linguagem, olhar vago, resistência ao toque, uso das pessoas como objetos e de brinquedos de forma não convencional, resistência a mudanças na rotina e no ambiente, fixação pelo movimento rotatório, movimentos rítmicos e estereotipados do corpo. (KANNER, 1966)

Percebemos que esse conjunto característico do autismo favorece uma concepção prévia de isolamento do autista e de negação de sua linguagem, mantendo o discurso de que a pessoa autista está ausente da possibilidade de linguagem, uma vez que duas das principais características - a dificuldade na comunicação e na interação - são requisitos para a definição de linguagem dentro de uma concepção linguística pautada na relação linguagem e comunicação.

Desta maneira, parece que o autismo vem acompanhado pelo signo linguístico 'não' na forma de um discurso social desanimador: não apresenta linguagem, não fala, está fora da linguagem, resiste ao contato de outras pessoas, foge ao olhar, não gosta de mudanças na rotina, não usa a imaginação de maneira adequada. Somados a estes aspectos, características sintomatológicas próprias do autismo, a exemplo de estereotipias motoras e vocais, são negadas enquanto linguagem dentro de uma concepção tradicional de assistência ao sujeito autista. Diante disso, parece que os sintomas negam o sujeito e a sua linguagem, colocando o autista no lugar do não, onde nada existe, onde nada seria possível. 
Todavia, na contramão desse discurso e baseados na perspectiva do funcionamento multimodal da linguagem, realizamos uma pesquisa observacional qualitativa, do tipo estudo de caso, para discutir o lugar de uma criança autista na linguagem a partir dos seus movimentos de negação que apresentam diferentes configurações multimodais do 'não' no autismo. Refletimos sobre as estereotipias motoras e vocalizações como indício de presença do sujeito autista na linguagem e enquanto matriz de significação em contextos de negação, tomando a linguagem enquanto funcionamento multimodal, conforme propõem Kendon (1982; 2000), McNeill (1985; 2000), Goldin-Meadow (2000), Cavalcante (2009) e Fonte et al (2014), uma vez que concebemos as estereotipias como possíveis marcadores multimodais carregados de sentido, tendo em vista que a matriz gesto-fala é inseparável.

\section{Estereotipias e linguagem}

Condutas estereotipadas foram encontradas em animais e no homem. Seu surgimento está frequentemente relacionado ao mau funcionamento do sistema de controle de conduta, impulsos e motivações no desempenho de algum movimento ou vocalização. Conforme a incidência, a qualidade dos episódios e a idade da criança, de uma forma ou de outra, as estereotipias comprometem o desenvolvimento motor, linguístico e as atividades físicas, sociais, emocionais, cognitivas e educativas. (HOFFMANN, 1996)

Etimologicamente, o termo estereotipia é composto pelos vocábulos gregos sterós, (sólido) e typos (modelo), que unidos carregam em sua essência um entendimento próprio: padrão rígido e estável. A Classificação Internacional das Doenças, em sua décima edição (CID-10), traz as estereotipias motoras como uma categoria nosográfica caracterizada por movimentos intencionais, repetitivos, estereotipados, ritmados, desprovidos de finalidade e sem relação a um transtorno psiquiátrico ou neurológico identificado. Esses movimentos caracterizam-se por balançar o corpo e/ou a cabeça, arrancar e/ou torcer os cabelos, estalar os dedos e bater as mãos. Porém, podem ter algum componente automutilador, sendo reconhecidos por bater a cabeça, esbofetear a face, colocar o dedo nos olhos, morder as mãos, os lábios ou outras partes do corpo.

Laznik (2004) informa que as estereotipias e automutilações surgem compondo o quadro do autismo no segundo ano de vida. No entanto, afirmamos que é comum observarmos em bebês condutas repetitivas que 
compõem o quadro do desenvolvimento psicomotor infantil, entre elas, o balanceio da cabeça buscando o equilíbrio em decúbito ventral, o balanceio de braços e pernas em decúbito dorsal, o balanceio do corpo ao se levantar quando sentada e o hábito de sugar.

Quanto ao fato da referência à "anormalidade" do movimento, é necessário lembrar que, assim como tiques e hábito motor, por exemplo, não são sinônimos entre si, mas categorizações de estereotipias, também não podemos considerar que os comportamentos estereotipados signifiquem, necessariamente, a presença de alguma patologia instalada. Padrões motores ou dislalias patológicas decorrentes de alterações psicomotoras ou de lesões neurológicas ocorrem frequentemente. No entanto, diariamente deparamos condutas estereotipadas de fundo social, moral, autoagressivo, educativo e de rituais, sem que sejam consideradas anormais. (HOFFMANN, 1996, s/p)

Entendemos que para se configurar como estereotipias no autismo, as condutas devem: reproduzir um padrão fixo de atividade, movimento ou vocalização; possuir características morfológicas semelhantes; obedecer a uma cadência de movimento, ritmo e sons; ser realizadas com ou sem objetos; ter uma constância; permanecer, sem pausas, num tempo próprio fora do domínio exterior e, aparentemente, não ter um objetivo determinado ou responder a algum estímulo do meio.

Os movimentos estereotipados, para Levin (1995), também chamados de movimentos autísticos, não se dirigem a ninguém e clausuram a relação da criança com o mundo exterior. São movimentos vazios, sem limites espaciais. Seguindo esta concepção de movimentos ausentes de significado e sentido, Bueno (2003, p. 155), afirma que "toda conduta estereotipada se produz de maneira independente da consciência do indivíduo, ou seja, considera-se ato automático que não tem significado evidente para o observador, embora possa daí inferir-se que a conduta é um processo de isolamento."

Compreendemos que no autismo há uma fragmentação da linguagem. Porém, em contrapartida às concepções acima apresentadas de que as estereotipias são desprovidas de significado e sentido, defendemo-las como lugar de sentido que, junto às vocalizações, configuram o funcionamento linguístico multimodal e inserem de maneira singular o autista na linguagem, constituindo-o como sujeito.

O sentido para nós difere do significado, este para o qual Mari (2008) atribui uma matriz conceitual associada ao item lexical, tal qual é concebida 
nos dicionários. O sentido seria um estágio posterior de significação, pois está ligado a uma intenção de uso. Dessa maneira, o sentido se constrói pelo sujeito. Para Coquet (2013, p. 02), "significar não é, pois, um ato puramente intelectual; não depende da simples cognição, pois implica também o 'eu posso' do ser como um todo, o corpo e a 'carne" ".

Benveniste (2006) esclarece a significação como algo que é próprio da linguagem: "Que a linguagem significa quer dizer que a significação não é qualquer coisa que lhe seja dada por acréscimo ou, numa medida mais ampla, por uma outra atividade; é de sua própria natureza; se ela não fosse assim, não seria nada" (BENVENISTE, 2006, p. 223). Para o autor, significar é ter um sentido atribuído por aqueles que utilizam a língua. Desse modo, ele une a significação à noção de sentido.

Acompanhamos Elia (2007) ao afirmar que os sentidos na linguagem são produzidos na ordem simbólica, seja ela falada ou não, incluindo nessa categoria os gestos, os desenhos, a dança, as expressões faciais e as narrativas orais. Essas manifestações simbólicas são "regidas pelo significante, e assim, ditas verbais, por estarem na dependência do verbo significante, e não por serem expressas via oral.” (ELIA, 2007, p. 21)

Se significar é ter um sentido para os que fazem uso da linguagem, assumimos a posição de que as estereotipias no autismo significam algo de acordo com o contexto em que surgem, apesar de Laznik (2011, p. 88) nos lembrar que "o enunciado de uma criança autista tem esse efeito característico de fazer pensar que ela não é portadora de nenhuma mensagem". Para a autora, as estereotipias são meios de descarga, manobras de evitamento e de defesa contra as lembranças ou percepções dolorosas provenientes do mundo exterior. "Portanto, essas condutas não têm (ou não têm mais) um objetivo de ato, elas não levam à encenação, à representação da ausência.” (LAZNIK, 2011, p. 77). Elas dizem algo do e pelo sujeito.

Impedidos de apelar à linguagem e sem articulação imaginária que permita perceber as coisas do mundo da mesma forma que seus semelhantes, produzem sintomas com seu corpo (estereotipias gestuais, "rocking", "flapyng", e outros movimentos rituais e repetitivos) no intento de, através da repetição, estruturar um mínimo de organização para suas vidas. (SIBEMBERG, 1998, p. 65)

Os movimentos estereotipados em rocking caracterizam-se pelo balanceio ritmado do corpo, já os movimentos em flapyng referem-se ao balanceio de mãos como tamborilar ou como se fora asas, que, para Levin 
(1997, p. 137), estariam relacionados a uma descarga de autoprazer: "A mão que está a serviço do prazer é uma mão que não explora nem investiga nada, uma mão que se ocupa de desligar a criança do campo do Outro ${ }^{1}$. Exemplo disto é a atitude corporal no autismo." No entanto, percebemos os movimentos manuais como uma descarga de excitação carregada de sentido, quando algo do ambiente é percebido pelo autista, a exemplo de Jorge ${ }^{2}$, a criança tratada neste artigo.

O sujeito é constituído na/pela linguagem, fruto das relações intercambiáveis entre o 'eu' e o 'tu' no processo enunciativo (BENVENISTE, 2005). O autor entende por enunciação a ação de colocar a língua em funcionamento por um ato individual de utilização, que pressupõe pessoas (eu-tu), espaço e tempo definidos, configurando, assim, o quadro enunciativo.

Durante o processo enunciativo o interlocutor reconhece o outro (locutor) como sujeito a partir dos fragmentos linguísticos, que, para nós são somados aos fragmentos corporais e gestuais produzidos. Há o 'eu' (locutor) que fala para um 'tu' (interlocutor) que atesta como linguagem as produções singulares do sujeito.

Vale destacar que os movimentos já são tomados como linguagem mesmo antes do nascimento da criança. Conforme afirmação de Levin:

Quando o pai e a mãe falam à criança in utero, muitas vezes esta responde através dos seus movimentos e reações tônicas que são percebidas pela mãe como os primeiros movimentos (os primeiros 'pontapés') aos quais dão um sentido, um valor discursivo e agem em consequência, e então se estabelece no imaginário parental um primeiro diálogo através do movimento. O dialogal se entretece deste modo com a motricidade e o contato que como efeito discursivo é produzido pelo movimento do feto ('aquele que cresce'). Os movimentos são ouvidos e, portanto, falam e são falados. (LEVIN, 1997, p. 217)

${ }^{1}$ O termo Outro foi utilizado por Lacan para designar um lugar simbólico: o significante, a linguagem, a lei, o inconsciente, que determina o sujeito, em alguns momentos de maneira externa a ele e em outros de maneira intrassubjetiva em sua relação com o desejo. Este termo pode ser grafado simplesmente com letra maiúscula, opondo-se ao termo escrito com minúscula que designa um outro imaginário ou lugar de alteridade especular ou ainda, ser escrito como grande Outro ou grande A, opondo-se ao pequeno outro ou ao pequeno a, respectivamente (ROUDINESCO; PLON, 1998).

${ }^{2}$ Utilizamos nomes fictícios neste artigo para salvaguardar a imagens dos sujeitos envolvidos no estudo. 
Admitimos um discurso formado por componentes verbais e não verbais que determina e constitui o sujeito. Não há, portanto, o verbo destituído do corpo, pois do corpo partem as primeiras iniciativas para o reconhecimento da linguagem.

\section{Multimodalidade: a matriz gesto-fala da linguagem}

Na perspectiva multimodal, a matriz da linguagem é constituída por produções vocais e gestuais, que estão incorporadas em um sistema integrado de significação. (KENDON, 1982, 2000; MCNEILL, 1985, 1992, 2000; BUTCHER; GOLDIN-MEADOW, 2000, CAVALCANTE, 2009 e FONTE et al, 2014), contribuindo para a produção de sentido na relação entre os sujeitos.

A concepção multimodal da linguagem também é defendida por Cosnier $(1977,1996,2004)$, que afirma que a comunicação humana mescla diferentes elementos, incluindo fala, mímicas faciais, gestos e mudanças posturais, que são percebidos por diferentes canais sensoriais, como o auditivo e o visual, por exemplo. Desse modo, as trocas interativas apresentam caráter multimodal e multicanal.

$\mathrm{Na}$ interação, entendida como espaço de relações compartilhadas e influência mútua entre os sujeitos, a linguagem pode ser constituída por diferentes elementos multimodais, os quais são estruturados pela oralidade e/ou pela gestualidade. Dependendo do sujeito e do momento, a fala ou a gestualidade é privilegiada na cena interativa. No caso específico de uma criança autista em que a linguagem pode ser caracterizada pela ausência de oralidade, atraso na aquisição, presença de alterações sintáticas e semânticas, o modo gestual da linguagem surge como aspecto relevante na constituição do sujeito e na significação da linguagem.

Em um ambiente, muitas vezes marcado pelo silêncio, qualquer gesto, expressão ou movimento corporal, mesmo que estereotipado, pode trazer algum sentido para aqueles que estão presentes na cena interativa. Acreditamos que, no autismo, não podemos perceber a linguagem simplesmente separando oralidade (fala) de gestos e movimentos corporais, procurando características que as consolidem em suas particularidades independentes. Faz-se necessário tomar a linguagem em seu conjunto multimodal em que um aspecto, gesto ou fala, auxilia ou confirma a sua estruturação. 
Em relação à matriz gesto-fala da linguagem, o gesto é constituído por imagem visual e mimética e a fala é composta por palavras codificadas. Desse modo, as produções vocais e as gestuais são formadas por processos distintos e independentes. (GOLDIN-MEADOW, 2009).

Os gestos são quaisquer movimentos de uma ou mais partes do corpo, que são realizados pelo sujeito no espaço das interações conversacionais. (LAVER; BECK, 2001). O termo gesto é percebido por McNeill (2000) no plural, pois há diversos movimentos corriqueiramente considerados gestos, que devem ser diferenciados. Para estudar os diferentes gestos, o autor adota a classificação da tipologia gestual: gesticulação, pantomima, gestos emblemáticos e Língua de Sinais, proposta por Kendon (1982). Interessanos aprofundar as discussões sobre gestos emblemáticos para compreender o emblema em contextos de negação.

Os gestos emblemáticos podem surgir na presença ou na ausência da fala e são parcialmente convencionais, pois são construídos socialmente e significados culturalmente (MCNEILL, 2000). Consideramos que os gestos de negação são emblemas frequentemente presentes nas relações entre sujeitos. Os gestos emblemáticos com sentido de negação, caracterizados pelo meneio de cabeça ou pelo movimento do dedo indicador no sentido horizontal, são construídos nas relações socioculturais vivenciadas pelos sujeitos.

Segundo Spitz (1998), os primeiros sinais semânticos do 'não', enquanto negação ou proibição, surgem na criança na forma de meneio de cabeça em torno do décimo quinto mês de vida e são inicialmente compreendidos antes de serem usados efetivamente por ela.

Acredito que o gesto de negação semântica de meneio de cabeça é o indicador visível do fato de que a abstração de uma recusa ou negação foi atingida pela criança. É a primeira abstração, e seu gesto simbólico representa o conceito abstrato da atitude: 'Eu não quero isso'. Nessa medida, é o primeiro passo em direção à função simbólica mais ampla no campo verbal, que se inicia na segunda metade do segundo ano. (SPITZ, 1998, p. 97)

Segundo o autor, o gesto de negação é adquirido através da identificação com o gesto do adulto. Os contextos de proibição/negação tendem a ser expressos verbalmente e enfatizados pelo adulto por gestos significativos, como balançar o dedo indicador e menear a cabeça. 
A negação desde sua origem se destaca pelo aspecto multimodal da linguagem. Entre o primeiro e o início do segundo ano de vida, as crianças podem apresentar diferentes movimentos que expressam negação, como: cobrir os olhos, abaixar a cabeça, afastar o rosto ou o esconder sob roupas ou cobertores, diferentemente dos adultos, que balanceiam a cabeça de um lado para o outro. (SPITZ, 1998)

O comportamento negativo de reclusão ou rejeição ao contato físico, o olhar vago dirigido ao ambiente e as estereotipias motoras, que a literatura especializada destaca como sintomas característicos do autista, é por nós entendido como maneiras encontradas por um sujeito de estar na linguagem através da negação. Seriam os primeiros modos não convencionais de o autista usar a linguagem e que comprometem o seu desenvolvimento linguístico.

Desta maneira, no 'não' encontramos modos particulares do autista estar na linguagem: por meio do corpo representado pelos gestos significativos, pelos movimentos de retração ou agressividade, através de estereotipias motoras e de vocalizações. Apesar de autores como Levin (1995) afirmarem o contrário: o corpo, as posturas, os tônus musculares, os movimentos e o silêncio no autismo estão numa posição de exclusão à linguagem.

O não gestual e corporal está no lugar da fala, ausente em alguns autistas, porém a recusa ao contato indica que algo caiu no campo da percepção, posto que só evitamos ou negamos aquilo que tomamos conhecimento. Martins e Barbosa (2007) destacam que, comumente, encontramos em artigos e trabalhos de cunho psicanalítico sobre o autismo, a afirmação de Lacan de que uma criança fecha seus ouvidos a alguma coisa que está sendo falada, se ela o faz assim, ela não está no pré-verbal, pois é do verbo que ela se protege.

Desta feita, acreditamos que o 'não' representado por estereotipias motoras, por gestos emblemáticos, por vocalizações, pelo desvio do olhar, entre outros recursos multimodais, marca a presença do autista na linguagem, mesmo que de maneira estranha. Logo, a linguagem se manifesta por meio de seu funcionamento multimodal e sempre revela algo do sujeito. 


\subsection{Contexto metodológico}

Este artigo é resultado de uma pesquisa qualitativa, do tipo estudo de caso, aprovada pelo Comitê de Ética da Universidade Católica de Pernambuco (UNICAP), sob processo número 012/2012 - CAAE 04020212.8.0000.5206, desenvolvida no Grupo de Estudos e Atendimento ao Espectro Autista- GEAUT/UNICAP. Considerando as questões éticas da pesquisa científica, os nomes dos envolvidos nas cenas analisadas serão fictícios para preservar a identidade dos sujeitos.

Participam deste Grupo, crianças com diagnóstico de Transtorno do Espectro Autista, entre a faixa etária de três a doze anos. Cada encontro possui duração aproximada de 45 minutos e tem a participação de três crianças, juntamente com uma estagiária de letras e outra de fonoaudiologia, uma fonoaudióloga, uma psicopedagoga e pesquisadores do Programa de Pós-graduação em Ciências da Linguagem.

O grupo de atendimento possibilita trocas coletivas entre os sujeitos envolvidos, promovendo o desenvolvimento individual e social dos autistas. Desse modo, o sujeito autista é percebido como aquele capaz de interagir e de compartilhar sentidos. Essa modalidade de atendimento "tem potencial para contribuir com a construção de 'seres na/da linguagem, ' capazes de vir a se inserir socialmente e de co-construir a própria história de vida." (PANHOCA; BAGAROLLO, 2007, p. 121)

A proposta do grupo é promover a linguagem e a socialização de crianças com diagnóstico de Transtorno do Espectro Autista em um programa de intervenção em grupo. Para sua efetivação, há encontros semanais entre os envolvidos, no qual os sujeitos participam de atividades lúdicas em que são exigidos a exploração e uso efetivo da linguagem e o convívio entre os pares.

Todos os encontros são filmados e transcritos com a utilização do software ELAN (EUDICO Language Annotator), que funciona como uma ferramenta de transcrição, possibilitando o registro de diferentes recursos multimodais da linguagem, como gestos e vocalizações, por exemplo, no tempo exato de sua ocorrência. Optamos por transcrever os gestos, as estereotipias motoras e as vocalizações, selecionando contextos de negação vivenciados pela criança autista participante deste estudo para compreendermos o seu lugar na linguagem a partir de discussões sobre diferentes configurações multimodais do 'não'. Desse modo, o corpus deste estudo foi constituído de fragmentos cujo conteúdo apresentava gestos, movimentos estereotipados motores e vocalizações em contexto de negação. 
A criança participante deste estudo, doravante Jorge, tem oito anos de idade, e foi diagnosticada como autista aos dois anos. É o único filho de um casal de pais jovens, sendo seu nascimento aguardado com satisfação. Segundo relato materno, andou e falou 'mamã' com um ano de idade. Após esse período apresentou mutismo. Durante seu desenvolvimento, foi observado comportamento autístico de usar as pessoas como objeto, não ter noção de perigo, agitações, movimentos estereotipados nas mãos e aversão ao toque. Atualmente, no GEAUT/UNICAP observamos agitação das mãos em ocasiões de grande excitação e tentativa de mordedura do joelho acompanhado de choramingo quando contrariado.

Jorge não apresenta intensa fuga do olhar ou aversão às pessoas, aceita beijos e abraços. Talvez, em virtude da rotatividade de estagiários, apresenta dificuldades em nomear os adultos que fazem parte do grupo. Reconhece e nomeia, apenas, a fonoaudióloga e coordenadora do grupo.

A linguagem oral da criança é caracterizada por palavras soltas e pequenas frases marcadas por alterações fonológicas e truncamentos que, em alguns momentos, dificultam a compreensão. Há presença da ecolalia 'tchau pessoal' e nomeação de cores e figuras quando está envolvida em uma atividade específica de desenho. Os olhares, gestos e movimentos, a exemplo de pegar as pessoas e levar para o que deseja, estão presentes na linguagem.

Jorge estuda em uma sala comum de uma escola particular da cidade do Recife. Acompanha e participa das atividades escolares com apoio de professores auxiliares, não havendo queixa quanto a sua inclusão. Faz uso de medicamento para controlar seus momentos de ansiedade e agitação.

\subsection{Discussões em torno das estereotipias e vocalizações}

No grupo de atendimento, Jorge é bastante participativo e resiste à entrada de outra pessoa nas atividades. Nesses momentos o 'não' está presente em suas ações e vocalizações com diferentes configurações multimodais: o não verbalizado, o não gestual e o não estereotipado. Em comum, todos apresentam algum sentido para os interlocutores, a exemplo dos fragmentos que serão apresentados a seguir.

Em um dos encontros do grupo, André, uma das crianças participantes, realizava atividade lúdica no computador, mediada pela psicopedagoga e pela fonoaudióloga. Jorge, que já tinha participado da atividade, mostrou-se insatisfeito em ceder seu lugar para o colega e aguardar novamente sua vez. Nesse contexto de frustração para Jorge a negação surge como tema central. 


\section{Fragmento I}

\begin{tabular}{|l|l|l|l|}
\hline Tempo inicial & Tempo final & Plano verbal & Plano gestual \\
\hline 00:00:14.520 & $00: 00: 20.860$ & $\begin{array}{l}\text { iii muito bem hummm nãaao } \\
\text { nãaao sai }\end{array}$ & $\begin{array}{l}\text { Abraçado com a fonoaudióloga, olha para } \\
\text { a tela do computador e gira seu corpo } \\
\text { tentando se soltar dos braços dela. A } \\
\text { terapeuta o abraça novamente, em seguida, } \\
\text { ele tenta se soltar dos braços dela mais } \\
\text { uma vez. }\end{array}$ \\
\hline
\end{tabular}

Nesse primeiro fragmento, a criança autista marca seu lugar na linguagem a partir de produções verbais e de movimentos gestuais, que confirmam sua insatisfação de aguardar sua vez e negam a participação do colega. Para isso, a criança produz o não verbalizado de forma enfática, pois alonga a duração de sua emissão. Na mesma ocorrência temporal, a terapeuta tenta conter a criança, de forma que ela não atrapalhe a participação da outra criança na atividade, mas Jorge resiste e não aceita, negando a participação de André por meio de movimentos corporais de girar o corpo e da tentativa de se soltar dos braços da terapeuta.

Neste contexto, os movimentos de girar o corpo não configuram estereotipia, tendo em vista que não há uma reprodução fixa, repetitiva e ritmada da ação. Outrossim, há nos movimentos um objetivo determinado marcado pelo 'não quero estar aqui' que provoca no interlocutor uma resposta contrária à desejada.

Constatamos que os gestos da criança estão integrados à sua fala, formando uma matriz única de significação, pois há uma sincronia temporal e semântica dos recursos multimodais, que simultaneamente produzem sentido de negação dentro do contexto. Em uma situação hipotética em que a linguagem não fosse percebida em seu conjunto, o movimento de girar o corpo efetuado por Jorge, poderia ser significado como comprovação do comportamento autístico de aversão à aproximação e toque de outra pessoa. Seria mais um sintoma e não uma possibilidade de linguagem.

No entanto, não observamos incoerência entre o verbal, o corporal e o mundo exterior no universo da criança autista em estudo, mas sua participação ativa dentro do processo dialógico por meio de movimentos que possuem seu significado socialmente reconhecido. Esclarecemos que, apoiados em Benveniste, entendemos como processo dialógico a co-construção intersubjetiva estabelecida entre parceiros enunciativos na interação. A união entre gestos e fala permite que, no exemplo acima, a expressão 'iii muito bem' não represente um simples recorte de fala ecoada, 
reproduzida a partir de uma possível marca de finalização comum às atividades escolares ('muito bem, você terminou. Não precisa fazer mais'), mas uma alternância de posição dialógica uma vez que o gesto do abraço da fonoaudióloga responde à produção linguageira da criança.

No fragmento a seguir, constatamos diferentes configurações multimodais que marcam o lugar da criança autista no contexto de negação, caracterizadas por vocalizações, gesto emblemático (meneio de cabeça) e estereotipias motoras (balançar as pernas). McNeill (2000) já chamava atenção para a possibilidade de o gesto emblemático vir acompanhado da produção vocal. Acrescentamos à observação do autor, que, no autismo, os gestos emblemáticos podem vir integrados às estereotipias motoras conforme corroboram os dados a seguir.

\section{Fragmento II}

\begin{tabular}{|l|l|l|l|}
\hline Tempo inicial & Tempo final & Plano verbal - & Plano gestual \\
\hline 00:00:26.780 & $00: 00: 34.090$ & ai ââââ hum hum humm & $\begin{array}{l}\text { Sentado na cadeira, olha para baixo, balança as } \\
\text { pernas tocando-as entre si e mexe a cabeça de } \\
\text { um lado para o outro com as mãos seguras no } \\
\text { assento da cadeira. }\end{array}$ \\
\hline
\end{tabular}

Nesse exemplo, percebemos que o significado do gesto emblemático de negação foi enfatizado pela vocalização de insatisfação ('hum hum humm') e pelas estereotipias motoras produzidas pela criança autista a partir do funcionamento multimodal de sua linguagem, evidenciada pela coincidência temporal entre o gesto e a vocalização. Além disso, percebemos uma coerência entre a gestualidade e a vocalização na produção de sentido em contexto de negação, o que desconfigura no discurso de Jorge a presença única da estereotipia.

O tipo de gesto emblemático de negação, virar a cabeça de um lado para o outro, é considerado por Spitz (1998) como um dos primeiros sinais semânticos do 'não' que surgem na criança, indicando que o significado de recusa ou negação foi alcançado. $\mathrm{O}$ autor destaca esse gesto simbólico como representativo da abstração da vontade: 'eu não quero'. Se o 'não' representado pelo meneio de cabeça já indica uma posição da criança dentro da linguagem a partir da tomada do lugar enunciativo 'eu', consideramos que o reconhecimento da presença do 'não' no autismo atesta a posição subjetiva ocupada pelo locutor. 
No entanto, as marcas do 'não', sobretudo gestual e corporal, no quadro de autismo comumente são percebidas pelo interlocutor do autista como simbólicas de um isolamento inerente ao transtorno, e não como uma possibilidade de linguagem. Essa posição assumida pelo interlocutor compromete no autismo a tomada de consciência de si mesmo por meio da oposição do par 'eu/tu' no discurso, uma vez que é impedido ao sujeito a possibilidade de comungar do espaço intersubjetivo advindo nos enunciados.

Assim como o gesto emblemático possui um significado sociocultural, algumas condutas estereotipadas, de acordo com Hoffmann (1996) também possuem caráter social, não se configurando como 'anormalidades'. Estão integradas ao comportamento cultural, a exemplo do balançar as pernas e pés indicando nervosismo ou ansiedade, tamborilar os dedos sobre superfícies em momentos de impaciência.

Jorge apresenta o balançar de pernas, acompanhado pela postura corporal tensionada: segurar o assento da cadeira, como sinais que confirmam sua posição contrária às decisões de mantê-lo afastado das atividades do computador. São gestos socialmente reconhecidos, não sendo exclusivos de um quadro autístico.

Consideramos no autismo, fundamental para o prognóstico a posição do interlocutor que reconhece nas vocalizações, nos gestos, nos emblemas e nas estereotipias uma possibilidade de linguagem. O estabelecimento do laço social, tecido e estruturado através do reconhecimento da linguagem no autismo, captura o sujeito e assegura seu lugar no espaço intersubjetivo.

\section{Fragmento III}

\begin{tabular}{|l|l|l|l|l|}
\hline Tempo inicial & Tempo final & $\begin{array}{l}\text { Plano verbal - } \\
\text { Criança }\end{array}$ & Plano gestual - Criança & $\begin{array}{l}\text { Plano verbal - } \\
\text { fonoaudióloga }\end{array}$ \\
\hline 00:00:43.580 & $00: 00: 48.480$ & $\begin{array}{l}\text { âmm in nãn nã } \\
\text { nãããm a nãm di } \\
\text { rrum }\end{array}$ & $\begin{array}{l}\text { levanta do colo da terapeuta , corre } \\
\text { para o fundo da sala dando pulos, } \\
\text { fazendo careta e balançando os braços }\end{array}$ & $\begin{array}{l}\text { Não é su sua ver } \text { Jé } \\
\text { esperar! }\end{array}$ \\
\hline
\end{tabular}

No fragmento III, observamos a presença de produção verbal (vocalizações), corrida, expressão facial (careta) e estereotipias motoras, caracterizadas pelos movimentos rítmicos e repetitivos de pulos e flapyng (balançar de braços como asas). O conjunto desses movimentos poderia configurar um quadro de comportamento hiperativo desvinculado de um contexto dialógico. No entanto, o interlocutor da criança a reconhece como 
sujeito de linguagem, ao encontrar sentido de negação nesses movimentos. Percebemos a presença do não verbalizado, do não gestual e do não estereotipado.

É na linguagem que reside a possibilidade de subjetividade, posto que ela sustenta diferentes recursos adequados para a sua personificação, a exemplo da fala, dos gestos, dos movimentos corporais, das expressões faciais e dos vocalizes. Observamos que as produções realizadas pela criança obtêm entendimento quando relacionadas ao contexto único e irrepetível da enunciação, identificando os sujeitos envolvidos no ato comunicativo. $\mathrm{Na}$ enunciação não há forma certa ou errada de se enunciar, mas o entendimento de que o sujeito se marca na linguagem ao se apropriar e fazer uso dela de maneira singular. Reconhecemos na vocalização 'nãn nã nãããm a nãm' fragmentos do 'não' verbalizado que ganham sentido na percepção do interlocutor e comprovam a singularidade da fala da criança autista. Nesse conjunto estão envolvidos elementos dêiticos - o espaço, o tempo e as pessoas (eu e tu), responsáveis por compor o quadro enunciativo, marcado no fragmento pela possibilidade de ser atribuído ao conjunto de vocalizações, expressão facial e estereotipias motoras o conceito de linguagem multimodal, desde que as estereotipias sejam reconhecidas como linguagem e surjam em resposta a um estímulo do meio, conforme o comportamento apresentado por Jorge.

Dessa maneira, concebemos as manifestações multimodais apresentadas como linguagem que produz sentido e auxiliam na constituição do sujeito autista, uma vez que conceituamos a linguagem como campo de constituição do sujeito, o que vai além de ser um instrumento de comunicação ou expressão do pensamento. A criança é identificada como sujeito de linguagem e expressa sua subjetividade. Os aspectos multimodais, sendo assim, permitem o questionamento entre o que seria uma conduta estereotipada e o que é linguagem, uma vez que estão em jogo elementos subjetivos e contextuais.

No Fragmento IV, a seguir, observamos unicamente a presença do plano gestual que poderia representar uma estereotipia motora comum ao autismo: colocar as mãos no ouvindo. No entanto apoiado no campo enunciativo, configura-se um novo sentido para o movimento autístico. 


\section{Fragmento IV}

\begin{tabular}{|l|l|l|l|}
\hline Tempo inicial & Tempo final & Plano verbal & Plano gestual \\
\hline 00:01:58.608 & $00: 02: 00.196$ & (sem fala $)$ & $\begin{array}{l}\text { olha para a terapeuta e fecha os ouvidos com } \\
\text { as mãos }\end{array}$ \\
\hline
\end{tabular}

O tema negação é representado na criança pela ação de colocar as mãos no ouvido. Essa ação representativa do não estereotipado configura-se como uma recusa da criança aos sons que vem do meio, no caso em estudo, aos discursos da fonoaudióloga e da psicopedagoga contrários à vontade infantil.

A ação de Jorge, que em outra posição poderia ser representativa de uma birra infantil, confirma sua presença na linguagem, uma vez que, ao fechar seus ouvidos, Jorge nega à verbosidade do interlocutor, protegendose da entrada do verbo, a exemplo do que nos diz Martins e Barbosa (2007, p. 59):

Abatidos por uma aflição, imediatamente, quase como um ato reflexo, nos dirigimos às crianças com perguntas e demandas, o que contribui para que elas fortaleçam seu isolamento, através de suas estereotipias ou mesmo colocando as mãos nos ouvidos. (...)

Aos poucos, vamos percebendo que este apagamento imposto a nós por estas crianças é o lugar em que devemos nos colocar, pois, quando consentimos a esse posicionamento, nos surpreendemos com alguns acontecimentos.

Distanciamo-nos da ideia tradicional de que as estereotipias no autismo restringem-se a movimentos corporais repetitivos sem fins comunicativos. Percebemos as estereotipias enquanto aspecto multimodal coatuante no contexto comunicativo, pois constitui a matriz de linguagem, contribuindo para a produção de sentido.

A mudança de percepção de sentido dos gestos e estereotipias no autismo, retirando-os do lugar de indicadores de isolamento para atribuirlhes concepção negativa a uma resposta do meio, apontam para a entrada ou permanência do sujeito na linguagem. 


\section{Considerações finais}

Concebemos a linguagem como um processo dialógico multimodal, no qual os interlocutores compartilham e usam diferentes modos semióticos na interação. Sua natureza multissemiótica revela que gesto e fala estão unidos em um único sistema para a produção de sentido da cena interativa.

Ao discutir o lugar de uma criança autista na linguagem a partir de diferentes aspectos multimodais do 'não', constatamos que estereotipias motoras e vocalizações, frequentemente não atestadas como linguagem, sendo consideradas desprovidas de sentido, apresentam significado de negação, marcando o lugar da criança na linguagem.

Os dados analisados ilustram diferentes configurações multimodais do 'não' no autismo. As vocalizações, os gestos emblemáticos e as estereotipias motoras em contexto de negação significaram a presença do sujeito autista na linguagem, uma vez que essas diferentes configurações multimodais de negação se constituem como recursos enunciativos da criança autista.

A matriz gesto-fala no autismo é significante para o entendimento do interlocutor em relação ao contexto único e irrepetível da enunciação. Dessa maneira, concebemos as vocalizações, os gestos e as estereotipias motoras como linguagem que produz sentido e auxiliam na constituição dos sujeitos autistas.

É primordial que terapeutas e demais interlocutores compreendam as pistas multimodais, gestuais ou vocais, da linguagem das crianças autistas inseridas no contexto interativo, para que possibilitem a promoção e constituição da linguagem, considerando, consequentemente, a saída do isolamento autístico. Entender uma estereotipia guiada pelo 'não' como possibilidade de linguagem, permite que pensemos no autismo como um modo peculiar de funcionamento subjetivo e consideremos, talvez, alguns comportamentos que a literatura científica e não científica destacam por estereotipias, como alguns sinais semânticos do 'não'.

Percebemos nas diferentes maneiras de manifestação do 'não': verbalizado, gestual e estereotipado, movimentos na linguagem da criança autista desse estudo em prol da conquista de um lugar de entendimento. $\mathrm{O}$ 'não' parece assumir a importância de marcar as manifestações multimodais da linguagem. Algo do social foi internalizado pela criança através do signo linguístico 'não', possibilitando que participe do patrimônio coletivo da língua. 


\section{Referências}

BENVENISTE, E. Problemas de linguística geral I. $5^{a}$ ed. Trad. Maria da Glória Novak e Maria Luisa Neri. Campinas, SP: Pontes, 2005. 387 p.

BENVENISTE, E. Problemas de linguística geral II. $2^{\mathrm{a}}$ ed. Trad. Eduardo Guimarães et al. Campinas, SP: Pontes, 2006. 294 p.

BUTCHER, C; GOLDIN-MEADOW, S. Gesture and the transition from oneto two-word speech: when hand and mouth come together. In: MCNEILL (ed.), Language and Gesture, Cambridge: Cambridge University Press, p. 235-257, 2000.

BUENO, J. S. Cegueira e estereotipias. In: MARTÍN, M.B.; BUENO, S.T. Deficiência visual: aspectos psicoevolutivos e educativos. Trad. Magali de Lourdes Pedro. São Paulo: Santos, p.153-160, 2003.

CAVALCANTE, M. Rotinas interativas mãe-bebê: constituindo gêneros do discurso. Investigações, Recife, v. 21, p. 153-170, 2009.

COQUET, J. C. A busca do sentido: a linguagem em questão. Trad. Dilson Ferreira Cruz. São Paulo: Editora WMF Martins Fontes, 2013. 360 p.

COSNIER, J. Communication non verbal et langage. Psychologie Médicale, v.9, n.11, p. 2033-2049, 1977.

COSNIER, J. Les gestes du dialogue, la communication non verbale. Rev. Psychologie de la motivation, 21, p. 129-138, 1996.

COSNIER, J. Le corps et l'interaction (empathie et analyseur corporel). Société Française de Psychologie, Paris 8-9 0ctobre, 2004.

ELIA, L. O conceito de sujeito. $2^{\mathrm{a}}$ ed. Rio de Janeiro: Jorge Zahar, 2007. 80 p.

FONTE, R. et al. A matriz gesto-fala na aquisição da linguagem: algumas reflexões. In: RÊGO BARROS, I. et al. Aquisição, desvios epráticas de linguagem. Curitiba: Editora CRV, p. 11-26, 2014.

GOLDIN-MEADOW, S. How Gesture Promotes Learning Throughout Childhood. Child Development.v. 3, n. 2, p. 106-111, 2009.

HOFFMANN, S. B. Estereotipias na infância. Porto Alegre - RS, 1996. Disponível em: http://www.diversidadeemcena.net/artigo21.htm. Acesso em: 10 dez. 2015.

KANNER, L. Psiquiatría infantil. Buenos Aires: Paidos e Psique, 1966. 747 p.

KENDON, A. The study of gesture: someremarks on its history. Recherches sémiotiques/semiotic inquiry 2, p. 45-62, 1982.

KENDON, A. Language and gesture: unity or duality? In: MCNEILL (ed.) Language and gesture, Cambridge University Press, 2000. p. 47-63.

LAVER, J.; BECK, Unifying principles in the description of voice, posture and gesture. In: CAVE, C.; GUAITELLA, I. Interations et comportement multimodaux dans la communication. Paris, L'Harmattan, p. 46- 63, 2001. 
LAZNIK, M. C. A voz da sereia: o autismo e os impasses na constituição do sujeito. Trad. Cláudia Fernandes Rohenkol et al. Salvador, BA: Ágalma, 2004. 211 p.

LAZNIK, M. C. Rumo à fala: três crianças autistas em psicanálise. Trad. Procópio Abreu. Rio de Janeiro: Companhia de Freud, 2011. 249 p.

LEVIN, E. A Clínica psicomotora: o corpo na linguagem. Trad. Julieta Jerusalinsky. Petrópolis: Vozes, 1995. 341 p.

LEVIN, E. A infância em cena: constituição do sujeito e desenvolvimento psicomotor. Trad. Endlich Orth e Ephraim Ferreira Alves. Petrópolis, RJ: Vozes, 1997. 285 p.

MARI, H. Os lugares do sentido. Campinas. SP: Mercado de Letras, 2008. 152 p.

MARTINS, C. R.; BARBOSA, M. T. Um possível trabalho com crianças autistas. In: RIBEIRO, J. M. L.C.; MONTEIRO, K. A.C. (org.). Autismo e psicose na criança: trajetórias clínicas. Rio de Janeiro:7Letras, p. 58-66. 2004.

MCNEILL, D. So you think gestures are nonverbal? Psychological Review. v. 92, n.3, p. 350-371, 1985.

MCNEILL, D. Hand and Mind: What Gestures Reveal About Thought. Chicago, IL: University of Chicago Press, 1992. 409p.

MCNEILL, D. Introduction. In: MCNEILL, D .(ed.). Language and Gesture. Cambridge: Cambridge University Press, 2000. p. 1-10.

ORGANIZAÇÃO MUNDIAL DA SAÚDE. CID-10 - Classificação Estatística Internacional de Doenças e Problemas Relacionados à Saúde. 10a rev. São Paulo: Universidade de São Paulo, 1997.

PANHOCA, I.; BAGAROLLO, M. F. Sujeitos autistas em terapêutica fonoaudiológica grupal. In: GUARINELLO, A.C. et al. Abordagens grupais em fonoaudiologia: contextos e aplicações. São Paulo: Plexus, p. 121-137, 2007.

ROUDINESCO, E.; PLON, M. Dicionário de psicanálise. Trad. Vera Ribeiro, Lucy Magalhães. Rio de Janeiro: Jorge Zahar, 1998.874 p.

SIBEMBERG, N. Autismo e linguagem. In Escritos da criança, n. 5, Centro Lydia Coriat, Porto Alegre: Linus Editores, p. 60-71 , 1998.

SPITZ, R. A. O não e o sim: a gênese da comunicação humana. $3^{\mathrm{a}}$ ed. Trad. Urias Corrêa Arantes. São Paulo: Martins Fontes, 1998. 157 p.

Data de submissão: 30/12/2015. Data de aprovação: 22/06/2016. 